\title{
A ALFABETIZAÇÃO MATEMÁTICA E AS PRÁTICAS DE NUMERAMENTO NA COMUNIDADE QUILOMBOLA DE SÃO FÉLIX: A PEDAGOGIA CRÍTICA E O CURRÍCULO EM AÇÃO
}

\author{
ALFABETIZACIÓN MATEMÁTICA Y PRÁCTICAS DE NUMERACIÓN EN LA \\ COMUNIDAD QUILOMBOLA DE SÃO FÉLIX: PEDAGOGÍA CRÍTICA Y \\ CURRÍCULO EN ACCIÓN
}

\begin{abstract}
THE MATHEMATICAL LITERACY AND AS NUMBERING PRACTICES IN THE QUILOMBOLA COMMUNITY OF SÃO FÉLIX: THE CRITICAL PEDAGOGY AND THE CURRICULUM IN ACTION
\end{abstract}

Denília Andrade Teixeira dos SANTOS ${ }^{1}$

Teodoro Adriano Costa ZANARDI ${ }^{2}$

RESUMO: Os saberes-fazeres matemáticos difundidos pelos moradores de comunidades quilombolas são contemplados nas práticas didático-pedagógicas, cotidianamente executadas em sala de aula? Como as diretrizes curriculares, que orientam os conteúdos escolares na Educação Básica, contemplam esses saberes? Essas questões, dentre outras, compõem uma pesquisa realizada de 2016 a 2018 em uma comunidade quilombola em Minas Gerais, apresentando, como objetivo principal, as práticas de Numeramento propostas aos estudantes em processo de alfabetização. Sob a luz de Paulo Freire e Ubiratan D'Ambrosio, a pesquisa adentra discussões marcadas pelas políticas públicas educacionais e a garantia de direitos que assegurem, aos estudantes pesquisados, a inclusão da diversidade nas práticas escolares, bem como uma educação de qualidade que prime pela manutenção e difusão da história e cultura local. Utilizando um aporte metodológico de caráter qualitativo, a pesquisa utiliza o círculo de cultura freireano como espaço de vivência dialógica, além de buscar reforço em instrumentos etnográficos, assegurando a fidedignidade das informações e dados coletados. Os resultados indicam a necessidade de práticas pedagógicas de resistência, com vista à revolução conceitual e práxis que, de fato, considerem a relação sujeito e objeto da aprendizagem.

PALAVRAS-CHAVE: Alfabetização matemática. Currículo. Numeramento. Educação quilombola. Pedagogia crítica.

RESUMEN: ¿Los conocimientos matemáticos difundidos por los habitantes de las comunidades quilombolas están incluidos en las prácticas didáctico-pedagógicas, que se realizan diariamente en el aula? ¿Cómo las pautas curriculares, que guían el contenido escolar en Educación Básica, contemplan este conocimiento? Estas preguntas, entre otras, componen una investigación realizada entre 2016 y 2018 en una comunidad de quilombolas en Minas

\footnotetext{
${ }^{1}$ Pontifícia Universidade Católica de Minas Gerais (PUC-MG), Belo Horizonte - MG - Brasil. Doutoranda no Programa de Pós-Graduação em Educação Educação. ORCID: https://orcid.org/0000-0001-8912-7566. E-mail: deniliaandrade@hotmail.com

${ }^{2}$ Pontifícia Universidade Católica de Minas Gerais (PUC-MG), Belo Horizonte - MG - Brasil. Professor Adjunto no Programa de Pós-graduação em Educação. Doutorado em Educação (PUC-SP). ORCID: https://orcid.org/00000003-4742-9288. E-mail: zanardi@pucminas.br
}

RIAEE - Revista Ibero-Americana de Estudos em Educação, Araraquara, v. 15, n. esp. 3, p. 2350-2368, nov., 2020. E-ISSN: 1982-5587 
Gerais, que presenta, como objetivo principal, las prácticas de numeración propuestas a los estudiantes en el proceso de alfabetización. A la luz de Paulo Freire y Ubiratan D'Ambrosio, la investigación entra en discusiones marcadas por políticas públicas educativas y la garantía de los derechos que aseguran, a los estudiantes encuestados, la inclusión de la diversidad en las prácticas escolares, así como una educación de calidad que sobresalga en mantenimiento y difusión de la historia y cultura local. Mediante un enfoque metodológico cualitativo, la investigación utiliza el círculo de la cultura freireana como un espacio para la experiencia dialógica, además de buscar el refuerzo en los instrumentos etnográficos, asegurando la fiabilidad de la información y los datos recopilados. Los resultados indican la necesidad de prácticas pedagógicas de resistencia, en vista de la revolución conceptual y la praxis que, de hecho, consideran la relación sujeto y objeto de aprendizaje.

PALABRAS CLAVE: Alfabetización matemática. Plan de estudios. Numeración. Educación quilombola. Pedagogía crítica

ABSTRACT: The Mathematical know-how disseminated by the inhabitants of the quilombola communities included in the pedagogical practices, performed daily in the classroom? How do curricular guidelines, which guide school content in Basic Education, contemplate these knowledges? These issues, among others, make up a survey carried out from 2016 to 2018 in a quilombola community of Minas Gerais, presenting, as main objective, the application numbering practices for students in the literacy process. In the light of Paulo Freire and Ubiratan D'Ambrosio, the research enters discussions marked by educational policies and guarantee of rights that guarantee, to the researched students, an inclusion of diversity in school practices, as well as a quality education that is primarily for the maintenance and dissemination of local history and culture. Using a qualitative methodological method, the research uses the Freirean culture circle as a space for dialogical experience, in addition to seeking reinforcement in ethnographic instruments, guaranteeing the reliability of the information and data collected. The necessary results for the need for resistance pedagogical practices, with a view to the conceptual revolution and praxis that, in fact, consider a subject relationship and object of learning.

KEYWORDS: Mathematical literacy. Curriculum. Numbering. Quilombola education. Critical pedagogy.

\section{Introdução}

Quando falamos da Matemática como disciplina escolar, somos remetidos a uma área de conhecimento presente na educação escolarizada desde a Educação Infantil, com práticas voltadas para operar com números e símbolos que, embora vivas nas práticas sociais dia-a-dia, são lembradas mais pelas dificuldades e complexidades de seus conteúdos ensinados na escola do que nas ações cotidianas nas quais saberes matemáticos tornam-se imprescindíveis.

Partindo dessa consideração, vale lembrar que a Matemática é formada por signos, símbolos e significados próprios que formam uma língua específica que precisa ser ensinada no processo de educação escolarizada como uma segunda língua. Por esse caráter que introduz 
saberes matemáticos em forma de conteúdos curriculares na vida de crianças que, certamente, já fazem uso de conceitos matemáticos desde a mais tenra idade, o ensino dessa área de conhecimento requer atenção e cuidados como todas as demais áreas. Entretanto, como os índices, como o IDEB ${ }^{3}$, que medem a proficiência dos estudantes da Educação Básica brasileira em Matemática, estão sempre em evidência, torna-se urgente que o processo de ensinoaprendizagem, assim como seus indicadores de qualidade, sejam revistos e redirecionados para aqueles que utilizarão seus conteúdos nas práticas cotidianas, e não apenas nas práticas escolarizadas: os estudantes.

As reflexões e considerações apresentadas neste artigo são um recorte de uma pesquisa para o doutorado em educação, cujo objetivo era conhecer as práticas matemáticas cotidianas da comunidade quilombola de São Félix e como estas dialogavam com os conteúdos curriculares matemáticos na escola. Dentre essas práticas, as atividades pedagógicas voltadas para o Numeramento estavam compreendidas na etapa de alfabetização dos estudantes atendidos em duas classes multisseriadas da escola localizada na comunidade quilombola.

A pesquisa utilizou, para coleta de dados, recursos da metodologia etnográfica e, sendo seu caráter qualitativo, buscou apresentar as práticas matemáticas desenvolvidas na comunidade quilombola por meio da observação participante, entrevistas, círculos de cultura e oficinas pedagógicas.

A Educação Quilombola, apesar das leis e diretrizes curriculares específicas, ainda é um desafio no que tange à qualidade, especialmente quando fatores como acesso à escola, qualificação docente, recursos financeiros e espaço físico adequado são agravados em virtude das políticas públicas que não se efetivam na garantia dos direitos assegurados pela disposição legal regida pela Constituição Federal (1998), Estatuto da Criança e do Adolescente (1990), Lei de Diretrizes e Bases da Educação Nacional (1996), dentre outras que contemplam as comunidades quilombolas.

Enfatiza-se, como uma das reflexões neste trabalho, a atuação de docentes pedagogos com o ensino da Matemática nos anos iniciais do Ensino Fundamental e, em diálogo com outras pesquisas, discute-se a funcionalidade da formação e a eficácia do professor pedagogo no atendimento aos conteúdos de áreas específicas.

Há pesquisas indicando que, ainda que haja a necessidade de rever a formação do pedagogo no que tange à Matemática, o curso leva seus profissionais à compreensão do sujeito da aprendizagem, como estes aprendem, além de analisar, de forma crítica, o ensino das técnicas

${ }^{3}$ IDEB: Índice de Desenvolvimento da Educação Básica.

RIAEE - Revista Ibero-Americana de Estudos em Educação, Araraquara, v. 15, n. esp. 3, p. 2350-2368, nov., 2020. E-ISSN: 1982-5587 
matemáticas desvinculadas das ações cotidianas dos sujeitos participantes de uma sociedade grafocêntrica.

A exemplo dessa constatação, a pesquisa desenvolvida por Mocrosky, Orlovski e Lidio (2019), demonstra que a Matemática presente nos cursos de Pedagogia vem, além de apontar as necessidades de modificações no próprio curso, no sentido de questionar o percurso formativo para o qual foi planejada, requerendo, também, "que a matemática se faça presente como produção humana, sem prescindir de seus aspectos teóricos e técnicos” (2019, p. 233), levando os pedagogos às possibilidades de "desenvolver modos de compreender e tomar para si aspectos do conhecimento matemático técnico-científico numa perspectiva articuladora de compreensões, formativa" (Idem).

As possibilidades aventadas pelos autores passam da formação às ações pedagógicas planejadas com o intuito de consolidar conteúdos curriculares que, dotados de intencionalidade pedagógica, formariam sujeitos autônomos e capazes de organizar sua vida pessoal, profissional e acadêmica.

Mas, com o advento da Educação Matemática, campo de estudos e pesquisas com foco no ensino e na aprendizagem da Matemática, os fundamentos da educação presentes na formação em Pedagogia ganham evidência e, juntamente com a Psicologia do desenvolvimento da aprendizagem, tem nas técnicas matemáticas um dos objetos da aprendizagem que estará presente na relação com o sujeito da aprendizagem.

Assim, habilidades matemáticas necessárias para as diversas etapas da vida em sua profusão de afazeres, tal como a Alfabetização Matemática, despontam com conceitos e conteúdos basilares para a continuidade da vida acadêmica, sendo também pré-requisitos para várias outras atividades em áreas de saberes diversificados, compondo o repertório de ensino do docente pedagogo.

\section{A Alfabetização Matemática e o Numeramento}

O processo de Alfabetização Matemática se dá desde a Educação Infantil, quando conceitos matemáticos são trabalhados com as crianças, envoltos em atividades lúdicas que, no universo da infância, ganha uma conotação do brincar, recheado de múltiplas aprendizagens.

As crianças, ao chegarem à escola para suas primeiras experiências na educação formal, já carregam conhecimentos matemáticos vivenciados em suas atividades cotidianas que, desde as brincadeiras e jogos até as tentativas de ensino por parte da família, compõem essa bagagem, ainda que repleta de informalidade e sem as técnicas matemáticas. 
Monique Deheinzelin (1998) confirma essa assertiva ao dizer que:

[...] as crianças já fazem Matemática, com independência dos adultos; contam pedrinhas, conchas ou bala; contam quantas bolas de gude possuem ou quantos pontos fizeram no jogo e, levados à situação de comerciantes- devido à injusta pobreza em que se encontra a maior parte da população infantil no país, fazem cálculos complicados de custos e trocos (DEHEINZELIN, 1998, p. 89).

Contemplando essa afirmativa à luz das atividades da infância da sociedade moderna urbana, quando a maior parte do tempo das crianças é vivida dentro de ambientes fechados, elas aprendem a Matemática presente nos jogos digitais e on-line ofertados por aplicativos em celulares, tablets e videogames, assim como a que está presente em canções, desenhos animados, vídeos e programas infantis com a finalidade de entreter, mas que também trazem uma gama de informações que formam conceitos e constroem saberes.

Nos anos iniciais do Ensino Fundamental, tal como em Língua Portuguesa, quando os estudantes têm seus primeiros contatos com os conteúdos curriculares da Matemática escolarizada e representam a base para conhecimentos que serão construídos posteriormente, faz-se necessário práticas pedagógicas que compreendam a aprendizagem da leitura e da escrita de uma linguagem que lhe é peculiar, bem como o ensino dos conceitos, sinais, signos e símbolos matemáticos que representam suas ideias fundamentais, de forma que os estudantes possam se expressar por meio dos mesmos, utilizando-os adequadamente em suas vivências sociais e culturais.

Para que ocorra alfabetização matemática, o sujeito necessita compreender os processos envolvidos na realização de determinada atividade ou resolução de situação problema. Além disso, deve realizar a leitura da linguagem matemática, para entender os significados que a compõe, indo além de decifrar números e símbolos.

Partindo dessa compreensão, o documento Elementos Conceituais e Metodológicos para Definição dos Direitos de Aprendizagem e Desenvolvimento do Ciclo de Alfabetização $\left(1^{\circ}, 2^{\circ}\right.$ e $3^{\circ}$ anos) do Ensino Fundamental, considera a Alfabetização Matemática como um longo processo, que possibilitará ao estudante a utilização das ideias matemáticas na resolução de situações problemas que ocorrem nas vivências sociais. Assim, o documento define a Alfabetização Matemática como:

A alfabetização matemática é o processo de organização dos saberes que a criança traz de suas vivências anteriores ao ingresso no Ciclo de Alfabetização, de forma a levá-la a construir um corpo de conhecimentos matemáticos articulados, que potencializem sua atuação na vida cidadã (BRASIL, 2012, p. 60).

RIAEE - Revista Ibero-Americana de Estudos em Educação, Araraquara, v. 15, n. esp. 3, p. 2350-2368, nov., 2020. E-ISSN: 1982-5587 
Nessa concepção está presente o domínio da linguagem matemática em uma aprendizagem que dialogue com as vivências sociais, utilizando instrumentos e práticas que fazem parte do nosso cotidiano e que estão repletos de conhecimentos matemáticos.

Ao complementar o conceito trazido pelo documento citado acima, a professora Sônia Ocsana Daniluk (2015) afirma que a Alfabetização Matemática está vinculada às ações voltadas à aprendizagem da leitura e da escrita da linguagem matemática nos anos iniciais do Ensino Fundamental:

Compreendo a alfabetização matemática, portanto, como fenômeno que trata da compreensão, da interpretação e da comunicação dos conteúdos matemáticos ensinados na escola, tidos como iniciais para a construção do conhecimento matemático. Ser alfabetizado em matemática, então, é compreender o que se lê e escreve, o que se compreende a respeito das primeiras noções de lógica, de aritmética e de geometria. Assim, a escrita e a leitura das primeiras ideias matemáticas podem fazer parte do contexto de alfabetização (DANILUK, 2015, p. 26).

Nesse ponto podemos reconhecer o quanto a Matemática, em seu processo de alfabetização, contribuiria para a compreensão de como o mundo e a sociedade organizam, classificam e processam as informações matemáticas presentes em nosso cotidiano, fazendo-o a partir de habilidades que são desenvolvidas, ensinadas, tendo alguém - neste caso, um professor - como mediador dessa aprendizagem, que se dá entre o objeto e o sujeito desta.

Então, reconhecendo na Matemática esse caráter formativo para a vida, adentramos, oportunamente, com a compreensão do Numeramento, ou seja, assim como o Letramento está para a Alfabetização em Língua Portuguesa, o Numeramento está para a Alfabetização Matemática, compreendendo a Alfabetização em seu sentido lato, ou seja, as práticas, usos e funções sociais da leitura e da escrita.

Por esse parâmetro pode-se compreender o Numeramento como os usos e funções dos conceitos matemáticos, bem como seus instrumentos nas vivências sociais e culturais nas quais estamos imersos diariamente, já que vivemos em uma sociedade grafocêntrica, que tem a escrita como habilidade relevante para a participação social.

O termo Numeramento, trazido pela Educação Matemática, e também conhecido como Numeracia ou Letramento Matemático, tem maior clareza na explicação apresentada por Fonseca (2014):

[...] os modos de conhecer, explicar, organizar, argumentar, decidir e apreciar dessas sociedades baseiam-se muito fortemente em critérios quantitativos, métricos ou classificatórios, que compõem o que chamamos de conhecimentos matemáticos. Desse modo, mesmo um leitor iniciante vai se 
deparar com textos em que aparecem preços, medidas, quantidades, gráficos ou tabelas. São folhetos de promoções em supermercados ou tabelas de preços de lanchonetes, rótulos de produtos, fichas de acompanhamento médico de crianças ou adultos, matérias de jornal ou na TV, divulgando fenômenos e pesquisas, e tantos outros textos que já devem aparecer nas classes de alfabetização. Eles trazem números, tabelas, gráficos, diagramas- que um leitor também precisa aprender a ler, pois é com base nessa leitura que muitas decisões são tomadas, tais como consumir ou mão um produto, escolher o que e onde se vai comprar, alterar um tratamento de saúde, escolher um candidato. A preocupação em entender os papéis dessa informação quantificada ou os efeitos de sentido que conferem aos textos é o que nos faz compreender o Numeramento como uma dimensão do Letramento (FONSECA, 2014, p. 235).

As estratégias presentes no processo pedagógico, nessa perspectiva, devem levar em consideração os conhecimentos prévios dos estudantes, bem como seus artifícios pessoais para resolver as situações problemas propostas, visto que as relações matemáticas podem ser observadas em todos os espaços sociais, incluindo aqueles divididos pelas crianças, seja em suas atividades de lazer, de socialização, culturais e educativas.

A Base Nacional Comum Curricular (2017), documento de caráter normativo, trata essa relação utilizando o conceito Letramento Matemático, o mesmo utilizado pelo Programa Internacional de Estudantes (PISA):

O Ensino Fundamental deve ter compromisso com o desenvolvimento do letramento matemático, definido como as competências e habilidades de raciocinar, representar, comunicar e argumentar matematicamente, de modo a favorecer o estabelecimento de conjecturas, a formulação e a resolução de problemas em uma variedade de contextos, utilizando conceitos, procedimentos, fatos e ferramentas matemáticas. É também o letramento matemático que assegura aos alunos reconhecer que os conhecimentos matemáticos são fundamentais para a compreensão e a atuação no mundo e perceber o caráter de jogo intelectual da matemática, como aspecto que favorece o desenvolvimento do raciocínio lógico e crítico, estimula a investigação e pode ser prazeroso (fruição) (BRASIL, 2017).

Então, a Alfabetização Matemática na perspectiva do Numeramento ou Letramento Matemático deve propor um trabalho pedagógico voltado para práticas diversificadas de leitura e escrita, no espaço escolar e fora dele, que contemplem as conexões matemáticas e sua relação com a geometria (espaço e forma), com as grandezas, medidas e seus instrumentos, com a resolução de situações problemas envolvendo tanto as finanças quanto outras relações do sistema de numeração decimal.

O trabalho pedagógico nessa perspectiva pode, como afirma o PCN Matemática (1997), levar-nos à constatação da relevância da Matemática para os afazeres do mundo do trabalho, da vida cotidiana, além de ser fundamental para a construção de saberes de outras áreas de 
conhecimento. Junto a tais pontos, leva-nos à "necessidade de reverter um ensino centrado em procedimentos mecânicos, desprovidos de significados ao aluno" (BRASIL, 1997, p. 15, grifo nosso).

Consoante às afirmações desse parâmetro curricular, o ensino da Matemática na etapa da Alfabetização, ao primar por práticas de Numeramento, alinharia seus modelos ao disposto no documento normatizador do currículo atual do Ensino Fundamental, a BNCC, que, na descrição das competências gerais da Educação Básica, indica a valorização da diversidade de saberes e vivências culturais (BRASIL, 2017, p. 9).

Em decorrência da valorização da diversidade e das culturas, além dos conhecimentos prévios dos estudantes circularem em sala de aula como elemento formativo, as peculiaridades de sua cultura seriam valorizadas e tomadas como conteúdo curricular, enriquecendo sua formação e fortalecendo sua identidade.

Dessa forma, proporíamos o ensino da Matemática pautado nos paradigmas do Programa Etnomatemática, o que contempla os objetivos da pesquisa aqui relatada, tendo como sujeitos os estudantes da escola quilombola de São Félix, pois esse programa preocupa-se em como se dá o ensino e a aprendizagem dos conteúdos matemáticos, bem como a seleção destes, a que grupo cultural se destina, problematizando situações reais, questionando "o aqui e agora" (D’AMBROSIO, 2009, p. 47).

Desta forma, conforme aponta a pesquisa, nada mais coerente do que os paradigmas da Etnomatemática para entrelaçar o ensino da Matemática na etapa da alfabetização na escola quilombola de São Félix.

\section{A Educação Quilombola e a comunidade de São Félix: práticas pedagógicas e o currículo}

Em 2011, ano em que o texto base para a elaboração das Diretrizes Curriculares para a Educação Quilombola foi redigido, muito já se havia discutido acerca da Educação Quilombola, e vários movimentos reivindicatórios foram deflagrados em busca da garantia do direito à educação emancipatória, comprometida com a equidade e com o compromisso de manter vivas a história e cultura dos quilombolas.

Cabe destacar que, durante décadas, os movimentos de luta empreendidos por grupos negros ou representantes destes tem assegurado com suor, sangue e luto, conquistas imensuráveis. A partir desses movimentos, outras ações são desencadeadas no sentido de garantir a efetividade de políticas públicas voltadas para a população negra e para as comunidades quilombolas. A Conferência Nacional de Educação (CONAE), realizada em 
2010, aponta em seu documento final a necessidade de legislação e diretrizes curriculares específicas para o atendimento aos estudantes das comunidades quilombolas.

O documento da CONAE traz à tona a importância da elaboração, tanto da legislação quanto da diretriz curricular, tendo a participação do movimento negro quilombola, pois assim assegurariam "o direito à preservação de suas manifestações culturais e à sustentabilidade de seu território tradicional" (CONAE, 2010, p. 131).

Assim, na construção das Diretrizes Curriculares para a Educação Quilombola, as demandas dos movimentos quilombolas encontraram ressonância em documentos legais como a Constituição Federal (1988), o Estatuto da Criança e do Adolescente (1990), a LDBEN (1996), vindo, em 2012, a Resolução número 8 (20/11/2012) que define, então, as diretrizes curriculares nacionais para a Educação Escolar quilombola na Educação Básica.

No quilombo de São Félix, antes que esse procedimento de titulação fosse iniciado pela Fundação Cultural Palmares em 2012 e, posteriormente, assumida pela equipe multidisciplinar do INCRA em parceria com a Secretaria Especial de Políticas Públicas para Igualdade Racial (SEPPIR), várias famílias já ocupavam o território localizado na cidade de Cantagalo, em Minas Gerais, região centro-nordeste do estado.

Antes mesmo que a certificação das terras na comunidade de São Félix fosse oficializada, foi fundada em novembro de 2007 a Escola Municipal São Félix Quilombola, passando a atender aos estudantes com idade para o Ensino Fundamental, do $1^{\circ}$ ao $5^{\circ}$ ano. Anterior à implantação dessa escola na comunidade, as crianças em idade escolar frequentavam a escola na zona urbana, distante cerca de 6 quilômetros de sua residência, o que elevava o número de evasão entre os estudantes quilombolas.

Mesmo com a escola implantada na comunidade, segundo Josiane, a representante da comunidade, as dificuldades não diminuíram, já que os docentes não atuavam considerando as práticas culturais e as vivências das crianças matriculadas na escola. Junto a esse fator, outras limitações se apresentavam, tal como a escassez de material e a distância do docente em relação à comunidade.

Com a chegada da professora Cleonice, em 2009, a oferta do trabalho pedagógico foi mudando, a partir de seu olhar atento sobre as especificidades culturais, históricas e identitárias dos estudantes quilombolas, que conforme o artigo $1^{\mathrm{o}}$ das Diretrizes Curriculares Nacionais para a Educação Escolar Quilombola na Educação Básica, a educação escolar:

$\mathrm{V}$ - deve garantir aos estudantes o direito de se apropriar dos conhecimentos tradicionais e das suas formas de produção de modo a contribuir para o seu reconhecimento, valorização e continuidade; VI - deve ser implementada

RIAEE - Revista Ibero-Americana de Estudos em Educação, Araraquara, v. 15, n. esp. 3, p. 2350-2368, nov., 2020. E-ISSN: 1982-5587 
como política pública educacional e estabelecer interface com a política já existente para os povos do campo e indígenas, reconhecidos os seus pontos de intersecção política, histórica, social, educacional e econômica, sem perder a especificidade (BRASIL, 2012, p. 3).

A pesquisa, desenvolvida de 2016 a 2018, teve contato com 3 docentes que afirmaram não terem recebido formação específica para o trabalho com estudantes quilombolas, ainda que a secretaria de educação local afirmasse o contrário.

Em 2016 e 2017 atuavam duas professoras, cada uma atendendo uma turma multisseriada, tendo a professora Josi trabalhando com a turma 1, com estudantes da Educação Infantil, $1^{\mathrm{o}}$ e $2^{\mathrm{o}}$ períodos e $1^{\mathrm{o}}$ ano do Ensino Fundamental, enquanto a professora Cleonice prestava atendimento aos estudantes do $2^{\circ}, 3^{\circ}, 4^{\circ}$ e $5^{\circ}$ anos do Ensino Fundamental na turma 2. Em 2018 uma terceira professora chega à escola com a incumbência dar aulas de reforço à aprendizagem dos estudantes com defasagem, especialmente no processo de alfabetização e na aprendizagem de conteúdos matemáticos, especificamente na unidade temática Números, segundo a BNCC.

Quando da observação das aulas na turma 1, foi possível perceber que a linguagem matemática utilizada é pautada nos modelos tradicionais, em torno dos algoritmos, da contagem e do sistema de numeração decimal. Palavras como continha, números, mais, menos, maior, menor, problema, dentre outras, que remontam aos conhecimentos matemáticos, estão presentes no vocabulário da docente e dos estudantes quando os conteúdos dessa área de conhecimento são abordados.

Neste aspecto, concordamos com Andrade (2009), ao afirmar que a linguagem matemática:

[...] não envolve a escrita e a leitura apenas de números e cálculos mas também de espaços, forma, medidas, grandezas, tratamento de informaçõescombinatória, probabilidade e estatística; uso de, por exemplo, unidades de medidas não-convencionais; construção, leitura e análise de gráficos e tabelas; registro e organização de informações coletadas etc., ou seja, leitura e escrita do mundo em que o indivíduo está inserido (ANDRADE, 2009, p. 158).

Embora não tenha observado, nos momentos em que estive em sala, uma abordagem mais ampla, como os pontos mencionados na afirmação de Andrade, quanto ao Numeramento, é evidente que a docente reconhece o termo, bem como sua relevância para a etapa de sua atuação. Entretanto, percebe-se que os conhecimentos culturais dos estudantes não ganham visibilidade na sala de aula, já que a docente prima por cumprir a orientação oriunda da secretaria de educação local, ensinando os conteúdos elencados nos documentos curriculares oficiais. 
Percebe-se uma prática pautada em paradigmas tradicionais, com atividades estanques, descontextualizadas, pré-prontas e que não permitem aos estudantes uma relação dos conteúdos escolares com suas vivências fora da escola. Para essas práticas, Paulo Freire (1993) afirma que ensinar e aprender não deveriam ser tratados de forma mecânica e, para que a ação pedagógica não seja autoritária, é necessário que os docentes saibam "o que se passa no mundo das crianças com quem trabalham. O universo de seus sonhos, a linguagem com que se defendem, manhosamente, da agressividade de seu mundo. $O$ que sabem e como sabem independentemente da escola" (FREIRE, 1993, p. 66).

Um dos adeptos da Pedagogia Crítica, Paulo Freire defende o diálogo como ação imprescindível à prática pedagógica e, ao dialogar com Ubiratan D’Ambrosio, precursor do Programa Etnomatemática, defendem a importância de que haja uma conexão dos saberes escolares com os saberes da vida. Para eles não há dicotomia entre esses saberes, sobretudo quando se valoriza os conhecimentos que circulam na sociedade como forma de despertar o estudante para sua realidade social, com vistas à transformação da mesma.

Compreendendo, em uma perspectiva crítica, o ensino da Matemática, Paulo Freire e D’Ambrosio conectam-se a outros pesquisadores como Skovsmose, e encontram no diálogo uma ferramenta pedagógica, principalmente quando se trata do espaço da sala de aula que pressupõe a investigação e a problematização. Por isso, o diálogo deve partir do professor em forma de um convite à investigação e os estudantes teriam de aceitá-lo, para que juntos, ainda que em papéis sociais distintos, consigam lidar com as diferenças (SKOVSMOSE, 2006, p. 129).

Essa forma de conceber o processo educacional pode ser encontrado na prática da professora Cleonice, atuante com a turma 2 da comunidade quilombola. Consciente da necessidade de práticas pedagógicas diferenciadas para os estudantes da comunidade quilombola, a docente se entende no papel de não apenas formar os estudantes, mas também seus familiares, a partir do momento em que estes são sujeitos de deveres e, conforme dita a lei, iguais em direitos, mas no que tange à educação, a lei lhes assegura um atendimento que leve em consideração suas necessidades.

Ela entende a importância da perpetuação da cultura local e diz compreender a necessidade de que houvesse um docente da própria comunidade a ensinar na escola, ministrando as aulas e conteúdos curriculares sistematizados, mas enriquecidos pela cultura local, valorizando seus saberes, modos de fazer e participar da vida em comunidade.

Ocorre em São Félix o mesmo que na comunidade quilombola de Cafundó, em pesquisa realizada por Dias, Rosseti e Romeiro (2018, p. 1574), quando membros mais antigos na 
comunidade se responsabilizam por repassar às novas gerações a cultura e história local, perpetuando a identidade do povo. Entretanto, com o advento das tecnologias, essas práticas culturais não têm chamado a atenção dos mais jovens, afastando-os de suas raízes, visto que "já nasceram na onda do capitalismo acentuado onde o avanço tecnológico provoca mais interesse" (DIAS; ROSSETI; ROMEIRO, 2018, p. 1574).

Esse é um motivo de preocupação da professora Cleonice que, ao olhar para a realidade em que atua, reforça a importância dos membros mais velhos da comunidade, assim como os moradores mais antigos, certa de que estes carregam consigo o patrimônio cultural da comunidade e que os tais deveriam ter espaço na escola, como componente curricular, para ensinar às crianças o modo de viver e de pensar da comunidade. Ela sonha com um projeto em que as ações voltadas para a multiplicação dos saberes locais, por meio dos idosos, seja sistematizado, conforme afirma:

\begin{abstract}
Docente: Pode levar seu filho sim pra buscar lenha quando você precisar. Pode levar pra ver você soprar um café, ver você peneirar um café, um urucum, por que? Nós temos que passar o que sabemos para os mais novos. Ah, eu aprendi essa cantiga de roda quando eu era pequeno, oh vamos falar pra ele, manda ensinar pra gente. Vem aqui também ensinar pra gente. Porque a gente está passando aquilo que nós sabemos, estamos resgatando, e depois vou passar pra vocês o que é a $L D B$, o que é a $L D B$ ? A lei do governo federal que manda fazer nas escolas de quilombolas. As escolas de quilombolas são completamente diferentes das escolas da cidade, é claro que nós estudamos a ciência, matemática, história, geografia. Mas, nós temos que ouvir os mais velhos, o projeto vem aí, os mais velhos não podem vir à escola, nós temos que ir aos mais velhos, entrevistar os mais velhos. Danças folclóricas tem que ter sim, tá, depois vou passar, né, tem uns lugarejos, vou pedir às pessoas pra poder (Transcrição de gravação, 2018).
\end{abstract}

Entretanto, apesar de todo seu esforço, a hegemonia cultural prevalece, inclusive, sobre as práticas pedagógicas que hierarquizam conteúdos curriculares, elegendo aqueles que deverão ser ensinados e a quem deverão ser ensinados, conforme D'Ambrósio denuncia: “A dignidade do indivíduo é violentada pela exclusão social, que se dá muitas vezes por não passar pelas barreiras discriminatórias estabelecidas pela sociedade dominante, inclusive e, principalmente, no sistema escolar" (D’AMBROSIO, 2009, p. 9).

Reconhecendo a falta de formação para o atendimento aos estudantes quilombolas, Cleonice tenta diversificar sua prática buscando aspectos da cultura local para a sala de aula. Nem sempre ela obtém êxito diante de um currículo imposto, e acaba por cumprir o oficial, sem grande significado cultural para os estudantes.

No que tange à Matemática, ela carrega consigo metodologias e estratégias didáticas orientadas pelo Pacto Nacional pela Alfabetização na Idade Certa (PNAIC), última formação 
docente ofertada pelo município em parceria com o governo federal, a qual orientou os alfabetizadores na adoção de ações que fomentassem a atenção para essa área de conhecimento, levando os estudantes ao entendimento dos conteúdos matemáticos presentes nos afazeres do dia-a-dia.

Segundo Barreto e Shimazaki (2019, p. 159), o PNAIC em Língua Portuguesa objetivava avaliar habilidades de leitura e escrita, voltadas para os gêneros textuais. Já em Matemática, os quatro eixos temáticos são focados tendo a resolução de problemas como metodologia de ensino dos conteúdos elencados pela diretriz curricular vigente.

Por essa diretriz dessa formação, há na sala de aula um cantinho da Matemática, onde é possível encontrar instrumentos de medida convencionais e não convencionais, como relógios, fita métrica, trena, garrafas e caixas; recursos para contagem e operações envolvendo os algarismos, como o ábaco, calculadora, tampinhas e palitos de picolé; jogos de carta, grãos para o jogo de bingo; aparelho de telefone; e outros materiais que pudessem ser úteis durante as aulas.

Tal como apontam Paulo Freire e D'Ambrosio, a docente está certa da importância de fomentar a história, a cultura e os saberes locais, promovendo aulas dialógicas, incentivando os estudantes a formularem perguntas e buscarem as respostas entre seus pares, promovendo desta forma amplos debates que, em determinados momentos, a docente via-se na obrigação de interromper e retomar os objetivos didáticos para o momento.

Os algoritmos tradicionais têm espaço cativo nas aulas de Matemática, já que para os gestores municipais estes devem ser consolidados com sucesso a fim de que os estudantes obtenham êxito nas avaliações externas. São trabalhados em resolução de problemas envolvendo as operações fundamentais do campo aditivo e do campo multiplicativo, com a concepção tradicional de problemas não contextualizados ou distantes das vivências das crianças.

Tal como a docente da turma 1 , a linguagem matemática utilizada nas aulas é voltada para a aprendizagem dos fatos fundamentais, para a resolução de problemas e algoritmos tradicionais. Por isso as palavras mais comuns são: continha, mais, menos, - às vezes substituídas por adição e subtração -, multiplicação e divisão, considerando o atendimento aos estudantes do segundo ciclo do Ensino Fundamental, $4^{\circ}$ e $5^{\circ}$ anos.

Essa linguagem não é comum entre os membros da comunidade, pois é possível ouvir expressões com conteúdos matemáticos sendo utilizados, com naturalidade, em situações do dia-a-dia, voltadas para o pagamento das contas, medidas diversas que vão desde a dosagem de vitamina para as galinhas poedeiras até a contagem dos dias, semanas ou meses para o plantio 
ou colheita de alguma cultura. De forma natural essa comunidade se vê embrenhada em ações matemáticas, assim como relataram à pesquisadora quando de uma roda de conversa: a medida do café, o horário de acordar as crianças, o cuidado com o preparo do almoço...

Sem o saber, essas relações matemáticas citadas pelas mulheres, mães e ou responsáveis pelas crianças da comunidade, foram elencadas por Paulo Freire quando em entrevista a D'Ambrosio:

Eu dizia outro dia aos alunos que quando a gente desperta, já caminhando para o banheiro, a gente já começa a fazer cálculos matemáticos. Quando a gente olha o relógio, por exemplo, a gente já estabelece a quantidade de minutos que a gente tem para, se acordou mais cedo, se acordou mais tarde, para saber exatamente a hora em que vai chegar à cozinha, que vai tomar o café da manhã, a hora que vai chegar o carro que vai nos levar ao seminário, para chegar às oito. Quer dizer, ao despertar os primeiros movimentos, lá dentro do quarto, são movimentos matematicizados. Para mim essa deveria ser uma das preocupações, a de mostrar a naturalidade do exercício matemático.

Com essa naturalidade apagada pelos conteúdos curriculares na sala de aula, as práticas de Numeramento são percebidas timidamente, sendo que o termo e sua aplicabilidade são de domínio da docente, tendo esta cursado o PNAIC e participado da construção de propostas metodológicas que ressignificassem o ensino da Matemática no processo de alfabetização. Ainda assim, sempre surgia uma novidade relacionada às vivências dos estudantes na comunidade.

A professora relata que ouvia as pessoas mais velhas da comunidade referindo-se à medição das terras, das colheitas de cereais e sementes com termos pouco usuais e que fugialhe à compreensão. Então, de forma brilhante, a docente torna-se pesquisadora de seu espaço de atuação e traz resultados espetaculares acerca da cultura local.

Para Freire a ação de pesquisar é parte integrante da ação docente, já que:

Não há ensino sem pesquisa e pesquisa sem ensino. Esses que-fazeres encontram-se um no corpo do outro. Enquanto ensino continuo buscando, reprocurando. Ensino porque busco, porque indaguei, porque indago e me indago. Pesquiso para constatar, constatando, intervenho, intervindo educo e me educo. Pesquiso para conhecer o que ainda não conheço e comunicar ou anunciar a novidade (FREIRE, 1996, p. 32).

E como resultado dessa pesquisa ela ensina a partir do que as crianças já conhecem, mas anuncia ao mundo a novidade: as unidades de medidas de capacidade e volume ainda utilizadas na comunidade, denominadas quarta, meia-quarta, neta, prato e meio-prato e utilizadas, especialmente, segundo a docente, para os produtos gerados no moinho d'agua, como o fubá e 
canjiquinha, tem instrumentos de medidas próprios, caixas de madeira confeccionadas pelos moradores.

A partir das informações sobre as unidades de medida coletadas entre os membros mais velhos da comunidade, a docente se propôs a trabalhar com as crianças tais informações e começou por questioná-los se conheciam as palavras que nomeavam as unidades de medidas. Como a resposta foi positiva ela passou a inquiri-los sobre pessoas, locais e tempo em que tais palavras eram utilizadas.

Assim, foi informada pelos estudantes que seus avós e algumas pessoas mais velhas, na comunidade, faziam uso contumaz das mesmas, quando se tratava de medir milho, fubá e canjica. Após a conversa inicial ela apresentou-lhes as caixas confeccionadas por si mesma, compondo seu planejamento para o ensino de frações. Segundo ela, a ideia surgiu da equivalência de valores presente na relação entre as unidades de medidas.

As dimensões das caixas, tal como as utilizadas no moinho, apresentam as medidas, conforme as anotações da docente: quarta: $32 \mathrm{~cm}$ x $31 \mathrm{~cm}$ x $20 \mathrm{~cm}$; Meia quarta: 26,5 cm x 27 cm x $14 \mathrm{~cm}$; Neta: $18 \mathrm{~cm}$ x 18,5 cm x $13 \mathrm{~cm}$; Prato: $14 \mathrm{~cm}$ x $15 \mathrm{~cm}$ x $10 \mathrm{~cm}$; Meio prato: 12 $\mathrm{cm} \times 13 \mathrm{~cm}$ x $7 \mathrm{~cm}$. Quanto ao volume, a quarta comporta $19.840 \mathrm{~cm}^{3}=0,01984 \mathrm{~m}^{3}$, a meiaquarta $1.0017 \mathrm{~cm}^{3}=0,010017 \mathrm{~m}^{3}$, a neta $4329 \mathrm{~cm}^{3}=0,004329 \mathrm{~m}^{3}$, enquanto o prato apresenta o volume de $2.100 \mathrm{~cm}^{3}=0,0021 \mathrm{~m}^{3}$ e o meio-prato $1.092 \mathrm{~cm}^{3}=0,001092 \mathrm{~m}^{3}$.

O projeto desenvolvido ganhou o nome de 'Medidas antigas' e o material utilizado passou a compor o ambiente de ensino da sala. A etapa anterior ao ensino do conteúdo de frações, utilizando as unidades de medidas da comunidade, consistiu em pesquisar e fotografar objetos antigos presentes nas casas dos moradores da comunidade, etapa que demandou a participação dos estudantes.

As fotografias compuseram um grande cartaz que ganhou lugar de destaque na sala de aula, sendo motivo de orgulho dos estudantes que, valorizados por auxiliarem na produção de seu próprio conhecimento, passam a entender-se como participantes do processo educacional.

Ao propor a participação dos estudantes, a docente utiliza-a para além da necessidade da criança de se sentir valorizada, mas traz a participação como um recurso metodológico que, se trabalhada com afinco, produzirá não apenas resultados educacionais, mas também dará ênfase à necessidade de participação individual e coletiva, como princípio para a formação humana que se pauta na transformação e desenvolvimento pessoal e coletivo.

Exatamente sobre esses comportamentos, conhecimentos e indivíduos está o olhar da Etnomatemática, ao contemplar o saber e o fazer matemáticos de forma contextualizada, 
buscando responder às demandas cotidianas, como forma de aprender a lidar com os problemas que despontam nas vivências diárias das pessoas e comunidades.

Como, segundo o autor, no cotidiano estão presentes os saberes e fazeres próprios da cultura, os indivíduos que destas participam estabelecem relações matemáticas presentes nos atos de comparar, classificar, quantificar, medir, explicar, generalizar e usar as ferramentas que são comuns à sua cultura, sejam eles de cunho material sejam intelectuais.

Então, ainda que a etnomatemática não seja aprendida nas instituições escolares, ela é aprendida nos lares, nas brincadeiras, entre amigos e familiares e até mesmo nas atividades laborais (D'AMBROSIO, 2009, p. 23).

A partir da experiência da professora Cleonice, é possível compreender que as práticas de Numeramento podem imbricar com a história e a cultura local e que a educação escolarizada e o currículo, elaborado para o atendimento às especificidades de formação dos quilombolas, podem constituir-se como espaço para a instrumentalização desses seres históricos e culturais em prol dessa luta, ainda inglória.

\section{Considerações finais}

A Pedagogia Crítica, tendo como foco a emancipação dos sujeitos da educação, bem como a transformação social a começar na escola, pelo processo de alfabetização, e tendo como aliado o currículo crítico, que mais que uma teoria pedagógica curricular, é um paradigma de transformação por meio da educação escolarizada, entende esta como espaço de luta, de defesa e de rompimento com a lógica mercadológica da manutenção da desigualdade social.

Para dar sustentação a essa Pedagogia, torna-se viável a compreensão de um currículo crítico que, para além de desvelar o caráter de reprodutor das mazelas sociais das teorias tradicionais de currículo, este colocará sob suspeição os conteúdos curriculares e as relações de poder adjacentes a este, perpassando a formação de docentes aos materiais e livros didáticos planejados para a educação escolarizada.

Faz-se necessário compreender o lugar do currículo como instrumento de garantia dos direitos ao conhecimento, assegurando-os aos sujeitos da ação educativa, situando o estudante na centralidade desse debate, desconstruindo as visões mercantilizadas, elitizadas, hierarquizadas e meritocráticas dos conteúdos escolares, dos sujeitos do processo educativo e do conhecimento. 
Sendo assim, o currículo compreende os sujeitos da educação e as práticas diversas exercidas por esses sujeitos, além das concepções de mundo e de educação que carregam consigo e os ensinam, mesmo não estando à frente de uma sala de aula.

Mas, o que dizer desse currículo na Educação quilombola? Assim como as lutas dos movimentos negros, longe de ter fim, está a qualidade da educação escolarizada destinada à população negra, especialmente aos quilombolas, considerando suas peculiaridades históricas e culturais na formação de sua identidade.

Mais que respostas, a pesquisa empreendida suscita outras questões que, como a Etnomatemática e a Pedagogia Crítica, tem na centralidade o sujeito da aprendizagem, bem como seus saberes, constituídos e construídos em relações sociais, familiares e laborais cotidianamente.

\section{REFERÊNCIAS}

ANDRADE, M. C. G. As inter-relações entre iniciação matemática e alfabetização. In: LOPES, C. A. E. Escritas e leituras na educação matemática. Belo Horizonte: Autêntica, 2009. p. 143-162.

BARRETO, L. C. D.; SHIMAZAKI, E. M. A formação de professores alfabetizadores para a educação inclusiva: um destaque ao pacto nacional pela alfabetização na idade certa. Revista Ibero-Americana de Estudos em Educação, Araraquara, v. 14, n. 1, p. 157-168, jan./mar. 2019. E-ISSN: 1982-5587. DOI: https://doi.org/10.21723/riaee.v14i1.11067

BRASIL, Ministério da Educação. Secretaria da Educação Básica. Elementos conceituais e metodológicos para definição dos direitos de aprendizagem e desenvolvimento do ciclo de alfabetização (10 $\mathbf{2}^{\mathbf{0}}$ e $3^{\mathbf{0}}$ anos) do Ensino Fundamental. Brasília, 2012.

BRASIL. Constituição (1988). Constituição da República Federativa do Brasil. Brasília, DF: Senado, 1988.

BRASIL. Decreto 7.352, de 04 de novembro de 2010. Dispõe sobre a política de educação do campo e o Programa Nacional de Educação na Reforma Agrária - PRONERA. Brasília, 2010. Disponível em: http://portal.mec.gov.br/docman/marco-2012-pdf/10199-8-decreto7352-de4-denovembro-de-2010/file. Acesso em: 10 set. 2020.

BRASIL. Lei n. 9.394, de 20 de dezembro de 1996. Lei de Diretrizes e Bases da Educação Nacional. Diário Oficial da União: Seção 1, Brasília, DF, n. 248, p. 27833, 23 dez. 1996.

BRASIL. Resolução n. 8, de 20 de novembro de 2012. Diretrizes Curriculares Nacionais para a Educação Escolar Quilombola na Educação Básica. Diário Oficial da União: Seção 1, Brasília, p. 26, 21 nov. 2012.

BRASIL. Secretaria de Educação Fundamental. Parâmetros Curriculares nacionais: matemática. Brasília: MEC/SEF,1997.

RIAEE - Revista Ibero-Americana de Estudos em Educação, Araraquara, v. 15, n. esp. 3, p. 2350-2368, nov., 2020. E-ISSN: 1982-5587 
D’AMBROSIO, U. Educação matemática: da teoria à prática. Campinas, SP: Papirus, 1996.

D’AMBROSIO, U. Etnomatemática: elo entre as tradições e a modernidade. Belo Horizonte: Autêntica Editora, 2009.

DANYLUK, O. S. Alfabetização matemática: o cotidiano da vida. 5. ed. Passo Fundo: Gráfica e Editora UFP, 2015.

DEHEINZELIN, M. A fome com a vontade de comer: uma proposta curricular de educação infantil. Petrópolis, RJ: Vozes, 1994.

DIAS, C. H. O.; ROSSETTI, R.; ROMEIRO, M. C. Educação de jovens e adultos na comunidade Quilombola do Cafundó. Revista Ibero-Americana de Estudos em Educação, Araraquara, v. 13, n. 4, p. 1568-1579, out./dez. 2018. E-ISSN: 1982-5587. DOI:

https://doi.org/10.21723/riaee.unesp.v13.n4.out/dez.2018.8845

FONSECA, M. C. F. R. Numeramento. In: FRADE, I. C. A. S.; VAL, M. G. C.; BREGUNCI, M. G. C. (Org.). Glossário Ceale: termos de alfabetização, leitura e escrita para educadores. Belo Horizonte: UFMG/ Faculdade de educação, 2014. p. 235-236.

FREIRE, P. Entrevista concedida a Ubiratan D’Ambrosio. 1996.

FREIRE, P. Pedagogia da autonomia. São Paulo: Paz e Terra, 1996.

FREIRE, P. Professora sim, tia não: cartas a quem ousa ensinar. São Paulo: Olho D’agua, 1993.

MOCROSKY, L. F. et al. O professor que ensina matemática nos Anos Iniciais: uma abertura ao contínuo acontecer histórico. Revista Ibero-Americana de Estudos em Educação, Araraquara, v. 14, n. 1, p. 222-236, jan./mar. 2019. E-ISSN: 1982-5587. DOI: https://doi.org/10.21723/riaee.v14i1.10894

SKOVSMOSE, O.; ALRO, H. Diálogo e aprendizagem em educação matemática. Belo Horizonte: Autêntica, 2006. 


\section{Como referenciar este artigo}

SANTOS, D. A. T.; ZANARDI, T. A. C. A alfabetização matemática e as práticas de numeramento na comunidade quilombola de São Félix: a pedagogia crítica e o currículo em ação. Revista Ibero-Americana de Estudos em Educação, Araraquara, v. 15, n. esp. 3, p. $2350-2368$ nov., 2020. 1982-5587.

DOI: https://doi.org/10.21723/riaee.v15iesp3.14442

Submetido em: 20/07/2020

Revisões requeridas em: 30/08/2020

Aprovado em: 29/09/2020

Publicado em: 30/10/2020 